\title{
Celecoxib enhances anticancer effect of cisplatin and induces anoikis in osteosarcoma via PI3K/Akt pathway
}

Bing Liu', Shigui Yan ${ }^{1 *}$, Liyan Qu ${ }^{2,3}$ and Jian Zhu

\begin{abstract}
Background: COX-2, an inducible enzyme, is associated with inflammatory diseases and carcinogenesis. Overexpression of COX-2 occurs in many human malignancies, including osteosarcoma. COX-2 positivity is form 67 to $92 \%$ in osteosarcoma, and COX-2 expresses 141-fold more in cancer stem cell spheres than daughter adherent cells. In our study, we have reported that celecoxib, a cyclooxygenase-2 inhibitor, induces apoptosis in human osteosarcoma cell line MG-63 via down-regulation of PI3K/Akt. It has been confirmed that celecoxib enhances apoptosis and cytotoxic effect of cisplatin, although the mechanism remains unclear.

Methods: We have attempted to identify the anti-proliferation of celecoxib, a selective COX-2 inhibitor, and the combination of celecoxib and cisplatin in MG-63 cells, and to explore the potential molecular mechanisms involved. MG-63 cells were treated with the combination of celecoxib and cisplatin or either agent alone for $48 \mathrm{~h}$ in serumsupplemented medium.

Results: MDR1, MRP1, BCRP and Trkb, E-cadherin, $\beta$-catenin were significantly downregulated in cells treated with the combination of celecoxib and cisplatin, and decreased $\beta$-catenin level was found in cells with wortmannin, a specific PI3K inhibitor.

Conclusion: Therefore, celecoxib enhances anticancer effect of cisplatin and induces anoikis in osteosarcoma, which may be PI3K/Akt-dependent, and MDR and $\beta$-catenin-related. PI3K may be at the center of the celecoxib effects, which play an essential role in the regulation of MDR and anoikis.
\end{abstract}

Keywords: COX-2, MDR, Anoikis, PI3K/Akt, Osteosarcoma

\section{Background}

The cyclooxygenase (COX) isoenzymes, known as prostaglandin (PG) rate-limiting synthase. COX-2, an inducible enzyme, is associated with inflammatory diseases and carcinogenesis, which is suspected to promote angiogenesis and tissue invasion of tumours $[1,2]$ and the overexpression of COX-2 has been mentioned in connection with resistance to apoptosis [3, 4]. Nonsteroidal anti-inflammatory drugs (NSAIDs) have been shown to induce apoptosis as well as potentiate the effect

\footnotetext{
*Correspondence: shiguiyan_zrgk@163.com

1 Department of Orthopedics, 2nd Affiliated Hospital, School of Medicine,

Zhejiang University, \#88 Jie Fang Road, Hangzhou 310009, Zhejiang,

People's Republic of China

Full list of author information is available at the end of the article
}

of chemotherapeutic agents including cisplatin $[5,6]$. Celecoxib is a NSAIDs that is a specific inhibitor of COX2. Although the precise mechanisms for the chemopreventive effects of celecoxib are not yet known, the ability of the inhibition of cell proliferation, and induction of apoptosis has been well-known [7, 8]. COX-2 is also involved in drug resistance and poor prognosis of tumor [9].

Osteosarcoma is the most common primary bone tumor in children and young adults, which has been reported to express COX-2 constitutively [10-12]. COX-2 positivity is form 67 to $92 \%$ in osteosarcoma $[13,14]$, and COX-2 expresses 141-fold more in cancer stem cell (CSC) spheres than daughter adherent cells [15]. Therefore, we can exert the drug to affect the 
over-expressed genes and achieve the therapies of human malignancies.

In our study, we have reported that celecoxib, a cyclooxygenase- 2 inhibitor, induces apoptosis in human osteosarcoma cell line MG-63 via down-regulation of PI3K/Akt [16]. It has been confirmed that celecoxib enhances the apoptosis induction and cytotoxic effect of cisplatin, although the mechanism remains unclear. COX-inhibitors may sensitize cancer cells to chemotherapeutic drugs via inhibiting P-gp, MRP1 and BCRP, and enhance the effect of anticancer drugs. PI3K/Akt plays an essential role in the cell/extracellar matrix (ECM) and cell/cell adhesion. Lack of the correct adhesion, the adhesion-dependent signals will be interrupted, which will result in adhesion-related apoptosis: anoikis. We have attempted to identify the anti-proliferation of celecoxib, a selective COX-2 inhibitor, and the combination of celecoxib and cisplatin in MG-63 cells, and to explore the potential molecular mechanisms involved.

\section{Methods \\ Reagents}

Celecoxib was generously provided by Pharmacia Cor. (New York, NY, USA) and dissolved in DMSO (40 mM) as a stock solution in $4{ }^{\circ} \mathrm{C}$. Cisplatin was purchased from Qilu Pharmaceutical Co., Ltd. (ShanDong province, China) and dissolved in normal saline $(2 \mathrm{mg} / \mathrm{ml})$ as a stock solution in $4{ }^{\circ} \mathrm{C}$. Celecoxib and cisplatin were added at various concentrations to cells in $10 \%$ fetal bovine serum (FBS)-containing DMEM. The final DMSO concentration never exceeded $0.1 \%(\mathrm{v} / \mathrm{v})$ after addition to medium. Mouse monoclonal antibodies specific for PI3K p110 (sc-8010), $\beta$-catenin (sc-7963); rabbit polyclonal antibodies specific for E-cadherin (sc-7870), Trkb (sc-8316), $\beta$-actin (sc-1616R);secondary antibodies were obtained from Santa Cruz Biotechnology, Inc.(Santa Cruz, CA, USA) were purchased from Calbiochem (San Diego, CA, USA).

\section{Cells and cell culture}

The human OS cell line MG-63 used in this study were obtained from American Type Culture Collection (Manassas, VA), and the U2OS cells were purchased from the ATCC (HTB-96; Rockville, Maryland, USA), HOS (CRL-1547TM, ATCC) was obtained from Cell Bank of Shanghai Institute of Biochemistry \& Cell Biology, Chinese Academy of Sciences (Shanghai, China). MG-63 Cells were grown in DMEM medium (Gibco Life Sciences) supplemented with $10 \%(\mathrm{v} / \mathrm{v})$ heat activated fetal bovine serum (Gibco Life Sciences) in a humidified atmosphere of $5 \% \mathrm{CO}_{2}$ at $37{ }^{\circ} \mathrm{C}$. U2OS cells were grown in RPMI1640 medium and HOS cells were grown in Eagle's Minimum Essential medium containing supplements as above.

\section{Real time quantitative RT-PCR analysis}

RNA was isolated from the cells using Trizol (Invitrogen) according to the manufacturer's instructions. cDNA was generated from total denatured RNA $(2 \mu \mathrm{g})$ by using $1 \mu \mathrm{l}$ oligo(dT) ${ }_{18}$ primer, 25 units RNase inhibitor, $2 \mu \mathrm{l}$ dNTPs $(10 \mathrm{mM})$, and a Moloney Murine Leukemia Virus reverse transcriptase cDNA synthesis kit (Promega, Madison, WI, USA). Quantitative real-time PCR was performed using Applied Biosystems 7500 Real-Time PCR System and SYBR ${ }^{\circledR}$ Premix Ex Taq ${ }^{\text {TM }}$ kit (Perfect Real Time) (TaKaRa, Dalian, China). Human 18s rRNA was used as internal control. The Cycle threshold (CT) values for each gene were corrected using the mean $\mathrm{CT}$ value. Real-time PCR data were quantified using the $\triangle C T$ method with

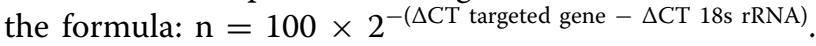
Targeted genes were amplified by real time PCR with the following primers: 18s rRNA forward: 5'GACTC AACACGGGAAACCTCAC3' and reverse: 5'CCAG ACAAATCGCTCCACCAAC3'; Human BCRP, forward 5'GCAGCAGGTCAGAGTGTGGTTT3', reverse 5'GCTGCAAAGCCGTAAATCCATA3'; Human MRP1 forward: $5^{\prime}$ CGCTGAGTTCCTGCGTACCTAT $^{\prime}$ and reverse: $5^{\prime}$ CCATTCTCCATTTGCTTTGCTT3', Human MDR1 forward: $5^{\prime}$ CCGTGGGGCAAGTCAGTTCAT3' and reverse: 5'CCTTCCAATGTGTTCGGCATTAG3'.

\section{Western blot analysis}

After the exposure for $48 \mathrm{~h}$, floating and adherent cells were harvested and rinsed twice with cold PBS and lysed in lysis buffer [50 mM Tris (pH 7.4), $400 \mathrm{mM} \mathrm{NaCl}$, $50 \mathrm{mM} \mathrm{NaF}, 30 \mathrm{mM}$ sodium $\mathrm{PP}_{\mathrm{i}}, 1 \mathrm{mM}$ sodium pyrovendidate, $1 \%$ SDS, and $0.5 \%$ NP40]. Protein concentrations were determined with bicinchoninic acid protein assay (Pierce, Rockford, IL, USA). Cellular proteins, at a concentration of $40 \mu \mathrm{g}$, were fractionated on $12 \%$ SDS-PAGE (Invitrogen/Novex, Carlsbad, CA, USA). Proteins were then transferred to a polyvinylidene difluoride membrane (Immobilon-P; Millipore, Bedford, MA, USA). The membrane was blocked with $5 \%$ nonfat milk in TBST and incubated overnight with antibody at $4{ }^{\circ} \mathrm{C}$. After washing three times with TBST, the membrane was incubated at room temperature for $1 \mathrm{~h}$ with horseradish peroxidase-conjugated secondary antibody diluted with TBST (1:1000). The detected protein signals were visualized by an enhanced chemiluminescence reaction system (Amersham, Arlington Heights, IL, USA), and the signal was visualized with X-ray film (Hyperfilm; Amersham). 


\section{Electrophoretic mobility shift assay (EMSA) for $\beta$-catenin activation}

Cells were treated with celecoxib (50 and $100 \mu \mathrm{mol} / \mathrm{l}$ ), cisplatin $(10 \mu \mathrm{g} / \mathrm{ml})$, and the combined administration for $48 \mathrm{~h}$. Nuclear proteins were prepared using nuclear and cytoplasmic protein extraction reagents according to the manufacturer's protocols (Pierce, Rockford, IL, USA). The crude nuclear pellet was suspended in $200 \mu \mathrm{L}$ buffer B (20 mmol/l HEPES pH 7.9; 25\% glycerol, $1.5 \mathrm{mmol} / \mathrm{l}$ $\mathrm{MgCl}_{2} ; 420 \mathrm{mmol} / \mathrm{l} \mathrm{NaCl}, 0.5 \mathrm{mmol} / \mathrm{l}$ DTT; $0.2 \mathrm{mmol} / \mathrm{l}$ EDTA; $0.5 \mathrm{mmol} / \mathrm{l} \mathrm{PMSF}$; and $4 \mu \mathrm{mol} / \mathrm{l}$ leupeptidin) and incubated on ice for $30 \mathrm{~min}$. The suspension was centrifuged at $16,000 \times g$ at $4{ }^{\circ} \mathrm{C}$ for $30 \mathrm{~min}$. The supernatant was collected as nuclear proteins. A non-radioactive EMSA was performed using an EMSA kit (Pierce, Rockford, IL, USA) according to the manufacturer's instructions. Nuclear protein $(4 \mu \mathrm{g})$ extracted from the cells or tissues was incubated with biotinylated oligonucleotides containing the $\beta$-catenin site for $30 \mathrm{~min}$ at room temperature. The samples were separated in a nondenaturing polyacrylamide gel (6\%, with $2.5 \%$ glycerol) and blotted on a Biodyne B $(0.45 \mathrm{~mm})$ positively charged nylon membrane (Pall Schweiz AG, Basel, Switzerland). The biotin was labeled with alkaline phosphatase-conjugated streptavidin and alkaline phosphatase was detected with Enhanced Chemiluminescense detection system (Santa Cruz, CA, USA).

\section{Statistical analysis}

The entire experiment was done in triplicate and the data are presented as mean \pm SD. The statistical significance of differences was determined by Student's two-tailed $t$ test in two groups and one-way ANOVA in multiple groups. $P<0.05$ was considered statistically significant. All data were analyzed with SPSS 16.0 software.

\section{Results}

\section{Down-regulation of MDR1, MRP1 and BCRP correlated} with increased apoptosis

We have reported that celecoxib caused G1 phase arrest and significantly inhibited cell growth, as well as potentiating cisplatin-induced apoptosis. MG-63 cells were exposed to celecoxib (50 and $100 \mu \mathrm{mol} / \mathrm{l}$ ), cisplatin $(10 \mu \mathrm{g} / \mathrm{ml})$, and the combined administration for $48 \mathrm{~h}$, and the apoptosis rate was $1.39,4.06,5.98,5.93,6.66$, $37.15 \%$, respectively, which may be result from COX2-related drug resistance. The activity of COX-2-PGE2Prostaglandin E Receptors signal pathway can upregulate the expression of all three ABC transporters, MDR1/P-gp (multidrug resistance/P-glycoprotein), MRP1 (multidrug resistance protein 1) and $\mathrm{BCRP}$ (breast cancer resistance protein), which encode efflux pumps, play important roles in the development of multidrug resistance [17].
The potential mechanism of MDR1, MRP1 and BCRP in celecoxib and/or cisplatin treated cells were therefore investigated. Figure 1 shows that the downregulation of MDR1, MRP1 and BCRP mRNA expression was found in cells treated with celecoxib (50 and $100 \mu \mathrm{mol} / \mathrm{l}$ ), cisplatin $(10 \mu \mathrm{g} / \mathrm{ml})$, and the combined administration for 48 h. Moreover, significant downregulation of MDR1, MRP1 and BCRP was detected in cells treated with the combination of celecoxib $(100 \mu \mathrm{mol} / \mathrm{l})$ and cisplatin compared with either agent alone, with apoptosis being strongly increased. However, no potentiation of celecoxib $(50 \mu \mathrm{mol} / \mathrm{l})$ and cisplatin was found. The results of treated MG-63 cells were similar in Western blot analysis (Fig. 2).

\section{Modulation of Trkb, E-cadherin and $\beta$-catenin expression in MG-63 cells treated with celecoxib and cisplatin}

We have reported that celecoxib, a cyclooxygenase-2 inhibitor, induces apoptosis in human osteosarcoma cell line MG-63 via down-regulation of PI3K/Akt. PI3K/ Akt plays an essential role in the cell/extracellar matrix (ECM) and cell/cell adhesion. Lack of the correct adhesion, the adhesion-dependent signals will be interrupted, which will result in adhesion-related apoptosis: anoikis [18]. Trkb, E-cadherin and $\beta$-catenin play an important role in the cell/cell adhesion [19]. In this study we found the down-regulations of E-cadherin and $\beta$-catenin in MG-63, U2OS and HOS cells, as shown in Fig. 3. Significant down-regulations of Trkb, E-cadherin and $\beta$-catenin activation were observed in MG-63 cells treated with cisplatin and celecoxib $(100 \mu \mathrm{mol} / \mathrm{l})$.

\section{The effect of celecoxib and cisplatin on nuclear expression of $\beta$-catenin}

As show in Fig. 4, constitutively active nuclear expression of $\beta$-catenin binding activity was observed in nuclear extracts from MG-63, U2OS and HOS cells. In all cells, compared with untreated control, both celecoxib and cisplatin treatment obviously decreased $\beta$-catenin binding activity, meanwhile, significant down-regulation of $\beta$-catenin binding activity was displayed in MG-63 and U2OS cells. These results suggest that celecoxib not only down-regulates $\beta$-catenin binding activity but also sensitizes cisplatin effect, which may be responsible for enhanced inhibition of cell viability and inducing apoptosis by combination treatment.

\section{PI3K inhibition by wortmannin causing to the decease of pAkt and $\beta$-catenin}

To investigate the role of PI3K in cells treated with celecoxib, we gave wortmannin $(1 \mathrm{mmol} / \mathrm{l})$ to cells for $48 \mathrm{~h}$, but did not see downregulation of total PI3K and Akt, although downregulation of pAkt (Thr308) and $\beta$-catenin was detected (Fig. 5). 

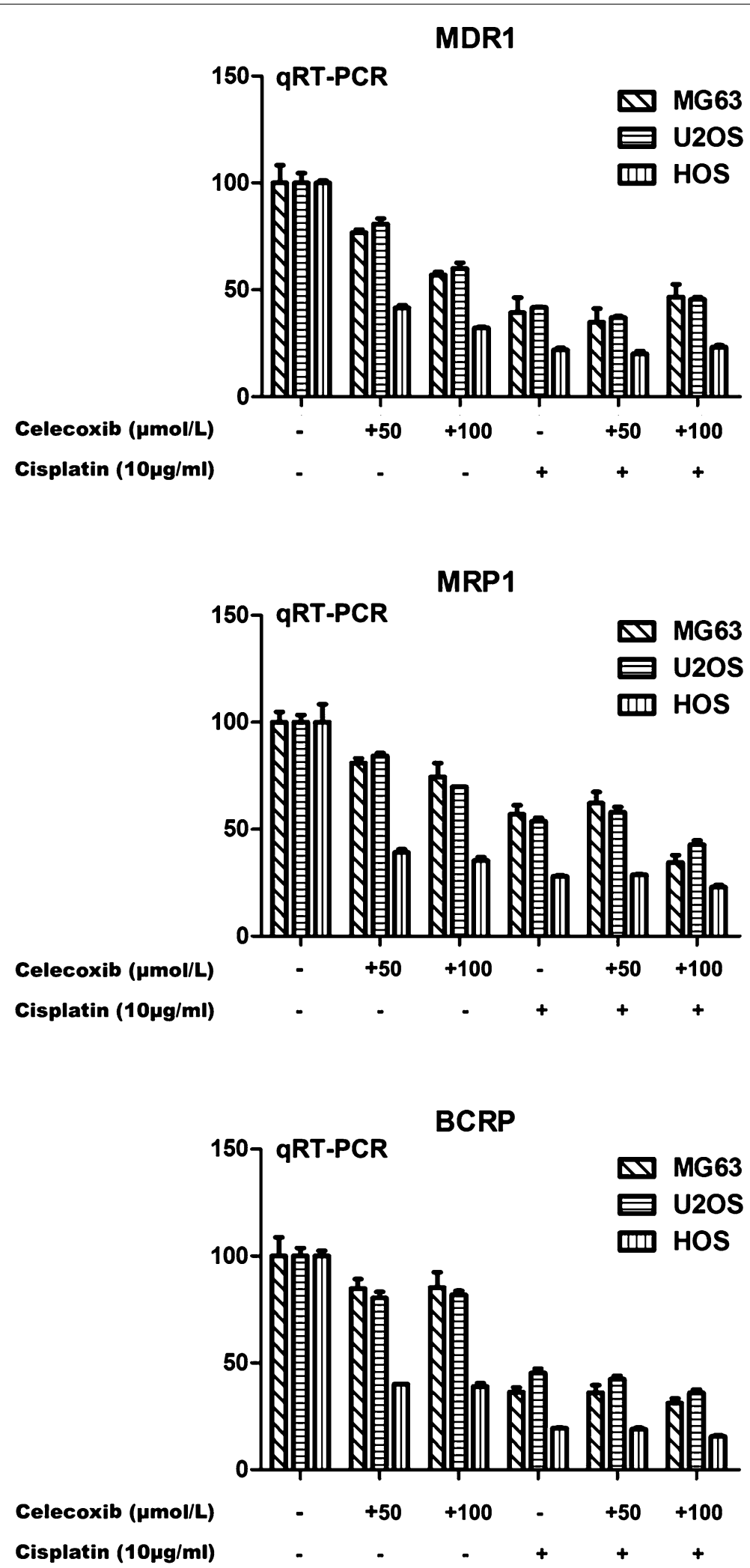

Fig. 1 Regulation of MDR1, MRP1 and BCRP expression. RT-PCR analysis MDR1, MRP1 and BCRP expression of MG-63 cells untreated or treated with celecoxib $(50,100 \mu \mathrm{mol} / \mathrm{l})$, cisplatin $(10 \mu \mathrm{g} / \mathrm{ml})$, and the combination for $48 \mathrm{~h}$. Significant down-regulation of MDR1, MRP1 and BCRP expression was observed in cells treated with cisplatin 


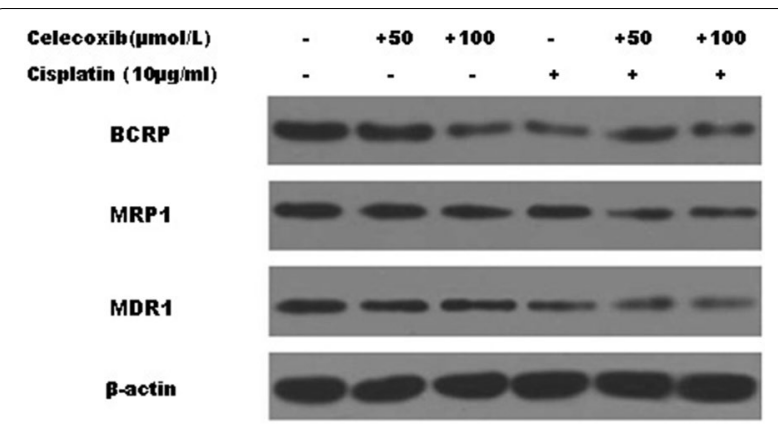

Fig. 2 Regulation of MDR1, MRP1 and BCRP expression. Western blot analysis MDR1, MRP1 and BCRP expression of MG-63 cells untreated or treated with celecoxib $(50,100 \mu \mathrm{mol} / \mathrm{l})$, cisplatin $(10 \mu \mathrm{g} / \mathrm{ml})$, and the combination for $48 \mathrm{~h}$. Significant down-regulation of MDR1, MRP1 and BCRP expression was observed in cells treated with cisplatin

\section{A hypothetical model for PI3K and COX-2 pathway interaction}

Celecoxib down-regulates the expression of PI3K/Akt, which plays an essential role in the regulation of MDR1, MRP1, BCRP and Trkb, E-cadherin, $\beta$-catenin, eventually causing anoikis. PI3K negatively regulates the expression of COX-2. It demonstrate that celecoxib enhances the anoikis induction and cytotoxic effect of cisplatin (Fig. 6).

\section{Discussion}

COX-2 is an inducible enzyme and associated with inflammatory diseases and carcinogenesis, which is suspected to promote angiogenesis and tissue invasion of tumors and resistance to apoptosis. COX-2 is also involved in drug resistance and poor prognosis of tumor. In the present study, it reveals that celecoxib and cisplatin inhibit cell growth via induction of apoptosis, and celecoxib potentiate the growth inhibition of cisplatin $[5,6]$. In our study, a significant reduction in cell viability and apoptosis in MG-63 cells treated with the combination of celecoxib and cisplatin as compared with either celecoxib or cisplatin alone was observed.

Recently, a causal link between COX-2 and MDR-1 gene expression, implicated in cancer chemoresistance, has been demonstrated. Patel et al. [20] showed that the overexpression of COX-2 leads to increased P-gp expression and activity, and this effect is dependent on COX-2 activity. In addition, COX-2 inhibitor was able to block the COX-2-mediated increase in MDR1 expression and activity [20]. It has revealed that the expression of COX-2 and the downstream enzyme involved in PGE2 biosynthesis, mPGES1, was correlated with P-gp and Bcl-xL [21]. COX-2 overexpression induced increased MRP-1 expression resulting in chemoresistance to cisplatin [22]. Strong positive correlation between the expression of COX-2 and MDR1/P-gp was also observed in hepatocellular carcinoma, breast cancer and ovarian cancer [23-25]. In addition, COX-2 may be a factor that can regulate the expression of all three $\mathrm{ABC}$ transporters: MDR1/P-gp, MRP1 and BCRP [26].

Nonsteroidal anti-inflammatory drugs (NSAIDs) have been shown to induce apoptosis as well as potentiate the effect of chemotherapeutic agents including cisplatin. Celecoxib is a NSAIDs which is a specific inhibitor of COX-2. NSAIDs and COX-2 selective inhibitors have been demonstrated to overcome MDR in many cancers. It has been suggested that COX-inhibitors may sensitize cancer cells to chemotherapeutic drugs via inhibiting P-gp, MRP1 and BCRP, and enhance the effect of anticancer drugs [27]. In imatinib-resistant $\mathrm{K} 562$ cells, celecoxib can inhibit COX-2 and down-regulate MDR-1 expression through Akt/p-Akt signaling pathway [27]. Akt/protein kinase $\mathrm{B}$ (PKB) belongs to the downstream molecules of PI3K, which plays an important role in PGE2-EP4 pathway, as shown above. COX-2 inhibitors are known to inhibit the PI3K/Akt pathway [28]. We have confirmed that celecoxib induces apoptosis in human osteosarcoma cell line MG-63 via down-regulation of PI3K/Akt, as well as potentiates the effect of cisplatin [16]. In breast cancer, COX-2 inhibitors can also inhibit P-gp expression and function [29]. Celecoxib down-regulated the expression of MRP1 protein in human lung cancer, which was accompanied by increased accumulation and enhanced cytotoxicity of doxorubicin [30]. Ko et al. [31] demonstrated that celecoxib reverses BCRP- and MRP1-related drug resistance via the down-regulation of MRP1 and BCRP mRNA in squamous cell carcinoma. Therefore, COX-2 may play an important role in upregulation the expression of MDR1/P-gp, MRP1 and BCRP via the COX-2-PGE2-EP4-PI3K pathway. In addition, COX-2 inhibitors can reverse the effects of COX-2. And the mechanisms of COX-2 inhibitors regulate the transcription of the MDR still do further research.

PI3K/Akt plays a central role in regulation of adhesion [32]. In cell/cell attachment, $\beta$-catenin serves as a component of the cytoskeleton [19]. $\beta$-catenin associates with the intracellular tail of the intercellular adhesion molecule E-cadherin [33]. Through this association, $\beta$-catenin plays an important role in strong cell-cell adhesion as it links E-cadherin to the actin cytoskeleton through the protein $\alpha$-catenin [34]. Another function of $\beta$-catenin is that maintaining cell-to-cell adhesion and mediating the Wnt/ $\beta$-catenin signal transduction pathway, which plays pivotal roles in embryogenesis and in malignant transformation of cells [35]. It has reported that E-cadherin is lost from cell-cell contacts before the execution of apoptosis [36]. Activation of PI3K/Akt signaling has been shown to mediate survival signals triggered by the engagement of E-cadherin [37] and other classical cadherins [38, 39]. 


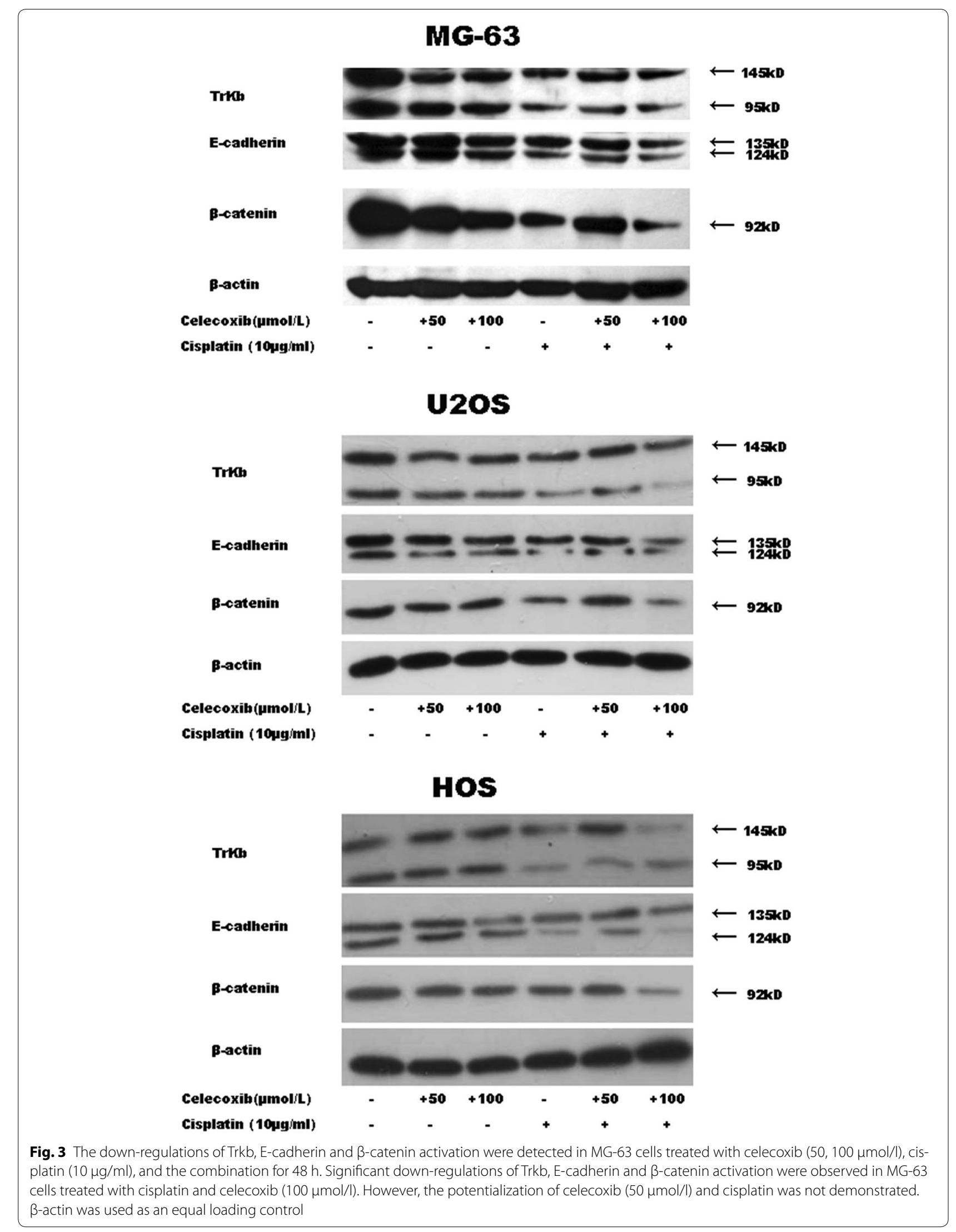



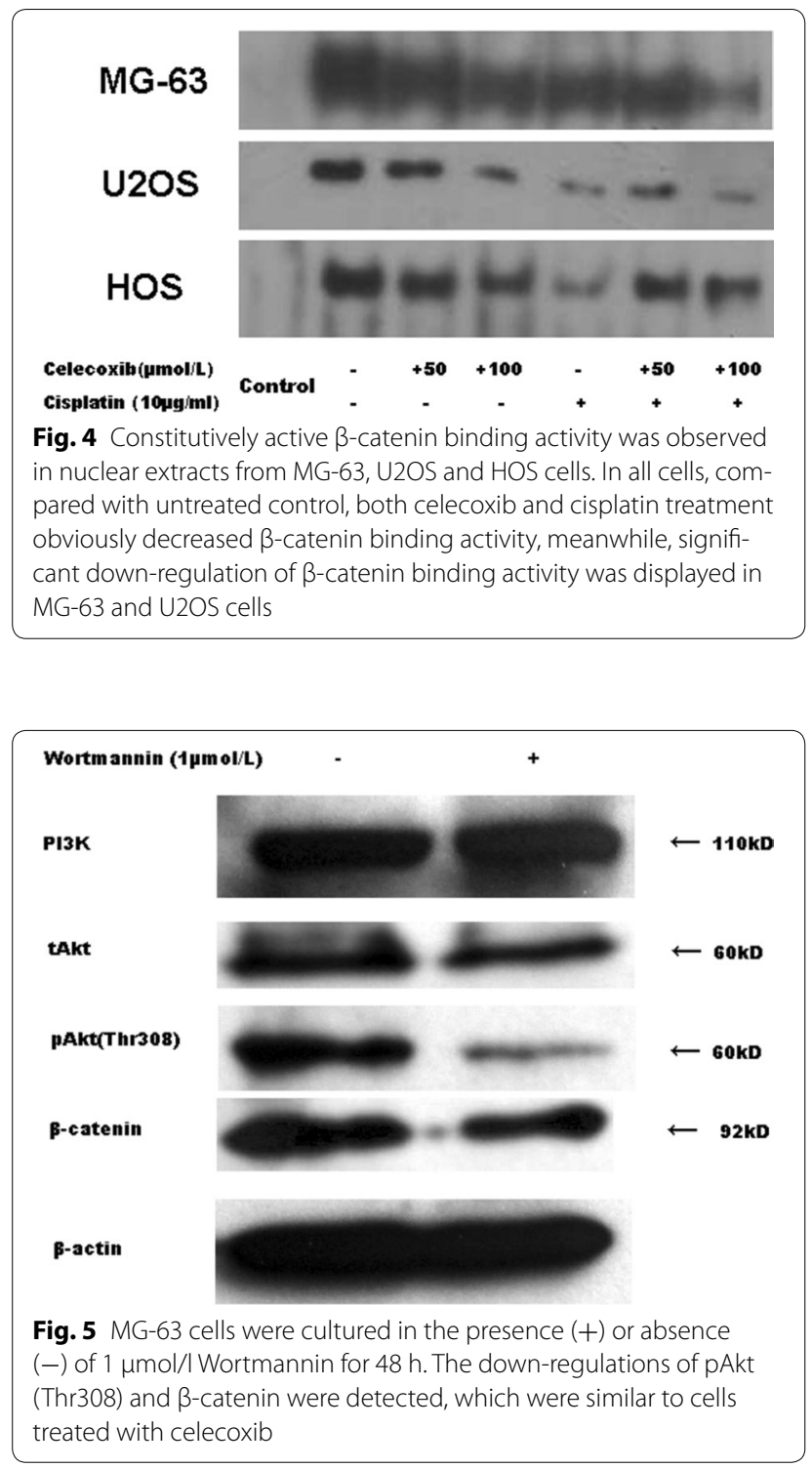

The present report suggests that $\beta$-catenin may also lie downstream of integrins. Several integrin-stimulated signaling pathways might lead to the induction of $\beta$-catenin signaling. One possible connection between integrins and $\beta$-catenin is the integrin-activated, antiapoptotic kinase PKB/Akt. PKB is known to inhibit the activity of glycogen synthase kinase $3-\beta$, a serine kinase that functions directly to reduce $\beta$-catenin protein and signaling $[40,41]$. It is possible that the result of these two inhibitory interactions is that activation of PKB by integrin signaling functions to positively activate $\beta$-catenin signaling. TrkB is a receptor tyrosine kinase that has brain-derived neurotrophic factor (BDNF) as one of its primary ligands. It has been established that BDNF binding to TrkB receptors results in a highly specific receptor

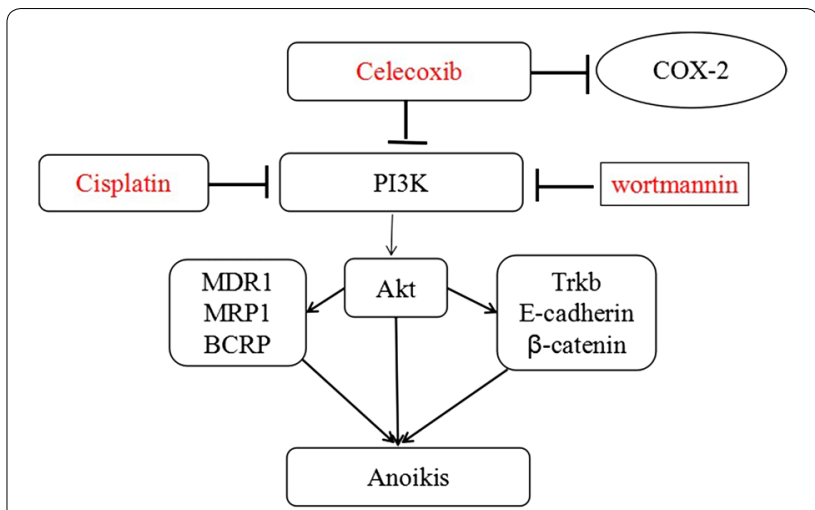

Fig. 6 A hypothetical model for PI3K and COX-2 pathway interaction. Celecoxib down-regulates the expression of PI3K/Akt, which plays an essential role in the regulation of MDR1, MRP1, BCRP and Trkb, E-cadherin, $\beta$-catenin, eventually causing anoikis. PI3K activity negatively regulates expression of COX-2

autophosphorylation [42] and in turn activates the PI3K/ Akt pathway [43].

In conclusion, MDR1, MRP1, BCRP and Trkb, E-cadherin, $\beta$-catenin were significantly downregulated in cells treated with the combination of celecoxib and cisplatin, and decreased $\beta$-catenin level was found in cells with wortmannin, a specific PI3K inhibitor. Therefore, celecoxib enhances anticancer effect of cisplatin and induces anoikis in osteosarcoma, which may be PI3K/ Akt-dependent, and MDR and $\beta$-catenin-related. PI3K may be at the center of the celecoxib effects, which play an essential role in the regulation of MDR and anoikis.

\section{Abbreviations}

COX: cyclooxygenase; PG: prostaglandin; NSAIDs: nonsteroidal anti-inflammatory drugs; CSC: cancer stem cell; ECM: extracellar matrix; MDR1/P-gp: multidrug resistance/P-glycoprotein; MRP1: multidrug resistance protein 1; BCRP: breast cancer resistance protein.

\section{Authors' contributions}

SY: experimental design and drafting the manuscript, BL: reading the literature and western blot, LQ: PCR. JZ: the contribution for revision. All authors read and approved the final manuscript.

\section{Author details}

${ }^{1}$ Department of Orthopedics, 2nd Affiliated Hospital, School of Medicine, Zhejiang University, \#88 Jie Fang Road, Hangzhou 310009, Zhejiang, People's Republic of China. ${ }^{2}$ Clinical Laboratory Centre, 2nd Affiliated Hospital, School of Medicine, Zhejiang University, \#88 Jie Fang Road, Hangzhou 310009, Zhejiang, People's Republic of China. ${ }^{3}$ Clinical Laboratory Centre, Binjiang Hospital of Hangzhou, Hangzhou, Zhejiang, People's Republic of China.

\section{Acknowledgements}

The study was supported by a grant from the Medical science and technology project of Zhejiang province of china (2016KYA096) and Natural Science Funds of Zhejiang Province (Y17H160033).

\section{Competing interests}

The authors declare that they have no competing interests. 


\section{Availability of data and materials}

Data sharing not applicable to this article as no datasets were generated or analysed during the current study.

\section{Funding}

The study was supported by a grant from the Medical science and technology project of Zhejiang province of china (2016KYA096) and Natural Science Funds of Zhejiang Province (Y17H160033)

Received: 7 June 2016 Accepted: 25 December 2016

Published online: 03 January 2017

\section{References}

1. Tsujii M, Kawano S, DuBois RN. Cyclooxygenase-2 expression in human colon cancer cells increases metastatic potential. Proc Natl Acad Sci. 1997:94:3336-40.

2. Tsujii M, Kawano S, Tsuji S, Saeaoka H, Hori M, DuBois RN. Cyclooxygenase regulates angiogenesis induced by colon cancer cells. Cell. 1998;93:705-16.

3. Tsujii M, DuBois RN. Alterations in cellular adhesions and apoptosis in epithelial cells overexpressing prostaglandin endoperoxide synthase 2 . Cell. 1995:83:493-501.

4. Nzeako UC, Guicciardi ME, Yoon JH, Bronk SF, Gores GJ. COX-2 inhibits Fas-mediate apoptosis in cholangiocarcinoma cells. Hepatology. 2002;35:552-9.

5. Lin J, Hsiao PW, Chiu TH, Chao Jl. Combination of cyclooxygenase-2 inhibitors and oxaliplatin increases the growth inhibition and death in human colon cancer cells. Biochem Pharmacol. 2005;70(5):658-67.

6. Mohammed SI, Craig BA, Mutsaers AJ, et al. Effects of the cyclooxygenase inhibitor, piroxicam, in combination with chemotherapy on tumor response, apoptosis, and angiogenesis in a canine model of human invasive urinary bladder cancer. Mol Cancer Ther. 2003;2:183-8.

7. Gupta RA, Dubois RN. Colorectal cancer prevention and treatment by inhibition of cyclooxygenase-2. Nat Rev Cancer. 2001;1:11-21.

8. Williams CS, Watson AJM, Sheng H, Helou R, Shao J, DuBois RN. Celecoxib prevents tumor growth in vivo without toxicity to normal gut: lack of correlation between in vitro and in vivo models. Cancer Res. 2000;60:6045-51.

9. Fantappiè $\mathrm{O}$, Solazzo M, Lasagna $\mathrm{N}$, et al. P-glycoprotein mediates celecoxib-induced apoptosis in multiple drug-resistant cell lines. Cancer Res. 2007;67:4915-23

10. Dickens DS, Kozielski R, Khan J, Forus A, Cripe TP. Cyclooxygenase-2 expression in pediatric sarcomas. Pediatr Dev Pathol. 2002;5:356-64

11. Dickens DS, Kozielski R, Leavey PJ, Timmons C, Cripe TP. Cyclooxygenase-2 expression does not correlate with outcome in osteosarcoma or rhabdomyosarcoma. Pediatr Hematol Oncol. 2003:25:282-5.

12. Naruse T, Nishida Y, Hosono K, Ishiguro N. Meloxicam inhibits osteosarcoma growth, invasiveness and metastasis by COX-2-dependent and independent routes. Carcinogenesis. 2006;27:584-92.

13. Masi L, Recenti $R$, Silvestri S, Pinzani P, Pepi M, Paglierani M, Brandi ML Franchi A. Expression of cyclooxygenase-2 in osteosarcoma of bone. Appl Immunohistochem Mol Morphol. 2007;15:70-6.

14. Rodriguez NI, Hoots WK, Koshkina NV, Morales-Arias JA, Arndt CA, Inwards CY, Hawkins DS, Munsell MF, Kleinerman ES. COX-2 expression correlates with survival in patients with osteosarcoma lung metastases. J Pediatr Hematol Oncol. 2008;30:507-12.

15. Pang LY, Gatenby EL, Kamida A, Whitelaw BA, Hupp TR, Argyle DJ. Global gene expression analysis of canine osteosarcoma stem cells reveals a novel role for COX-2 in tumour initiation. PLOS ONE. 2014:9(1):e83144.

16. Liu B, Shi ZL, Feng J, Tao HM. Celecoxib, a cyclooxygenase-2 inhibitor, induces apoptosis in human osteosarcoma cell line MG-63 via downregulation of PI3K/Akt. Cell Biol Int. 2008;32:494-501.

17. Liu B, Qu L, Tao H. Cyclo-oxygenase 2 up-regulates the effect of multidrug resistance. Cell Biol Int. 2009:34(1):21-5.

18. Ruoslahti E, Reed JC. Anchorage dependence, integrins, and apoptosis. Cell. 1994:77:477-8.

19. Polakis $P$, Hart $M$, Rubinfeld B. Defects in the regulation of $\beta$-catenin in colon cancer. Adv Exp Med Biol. 1999:470:23-32.
20. Patel VA, Dunn MJ, Sorokin A. Regulation of MDR1 (P-glycoprotein) by cyclooxygenase-2. J Biol Chem. 2002;277:38915-20.

21. Nardone G, Rocco A, Vaira D, et al. Expression of COX-2, mPGE-synthase1, MDR-1 (P-gp), and BCl-XL: a molecular pathway of H pylori-related gastric carcinogenesis. J Pathol. 2004;202:305-12.

22. Saikawa Y, Sugiura T, Toriumi F, et al. Cyclooxygenase-2 gene induction causes CDDP resistance in colon cancer cell line, HCT-15. Anticancer Res. 2004;24:2723-8.

23. Ziemann C, Schäfer D, Rüdell G, et al. The cyclooxygenase system participates in functional Mdr1 b overexpression in primary rat hepatocyte cultures. Hepatology. 2002;35:579-88.

24. Surowiak P, Materna V, Denkert C, et al. Significance of cyclooxygenase 2 and MDR1/P-glycoprotein coexpression in ovarian cancers. Cancer Lett. 2006:235:272-80

25. Surowiak P, Materna V, Matkowski R, et al. Relationship between cyclooxygenase 2 and P-glycoprotein expressions in invasive breast cancers and their prognostic significance. Breast Cancer Res. 2005;7:R862-70.

26. Surowiak P, Pawełczyk K, Maciejczyk A, et al. Positive correlation between cyclooxygenase 2 and the expression of $A B C$ transporters in non-small cell lung cancer. Anticancer Res. 2008;28:2967-74.

27. Arunasree KM, Roy KR, Anilkumar K, et al. Imatinib-resistant K562 cells are more sensitive to celecoxib, a selective COX-2 inhibitor: role of COX-2 and MDR-1. Leuk Res. 2008;32:855-64.

28. Arico S, Pattingre S, Bauvy C, et al. Celecoxib induces apoptosis by inhibiting 3-phosphoinositide-dependent protein kinese-1 activity in the human colon cancer HT-29 cell line. J Biol Chem. 2002;277:27613-21.

29. Zatelli MC, Luchin A, Tagliati F, et al. Cyclooxygenase-2 inhibitors prevent the development of chemoresistance phenotype in a breast cancer cell line by inhibiting glycoprotein p-170 expression. Endocr Relat Cancer. 2007; 14:1029-38.

30. Kang HK, Lee E, Pyo H, Lim SJ. Cyclooxygenase-independent downregulation of multidrug resistance-associated protein-1 expression by celecoxib in human lung cancer cells. Mol Cancer Ther. 2005:4:1358-63.

31. Ko SH, Choi GJ, Lee JH, et al. Differential effects of selective cyclooxygenase-2 inhibitors in inhibiting proliferation and induction of apoptosis in oral squamous cell carcinoma. Oncol Rep. 2008;19:425-33.

32. Alahari SK, Reddig PJ, Juliano RL. Biological aspects of signal transduction by cell adhesion receptors. Int Rev Cytol. 2002;220:145-84.

33. Ozawa M, Baribault H, Kemler R. The cytoplasmic domain of the cell adhesion molecule uvomorulin associates with three independent proteins structurally related in different species. EMBO J. 1989;8:1711-7.

34. Kemler R. From cadherins to catenins: cytoplasmic protein interactions and regulation of cell adhesion. Trends Genet. 1993;9:317-21.

35. Fuchs SY, Ougolkov AV, Spiegelman VS, Minamoto T. Oncogenic beta-catenin signaling networks in colorectal cancer. Cell Cycle. 2005:4(11):1522-39.

36. Fouquet S, Lugo-Martínez VH, Faussat AM, Renaud F, Cardot P, Chambaz $\mathrm{J}$, Pincon-Raymond $\mathrm{M}$, Thenet $\mathrm{S}$. Early loss of E-cadherin from cell-cell contacts is involved in the onset of anoikis in enterocytes. J Biol Chem. 2004:41:43061-9.

37. Bergin E, Levine JS, Koh JS, Lieberthal W. Mouse proximal tubular cell-cell adhesion inhibits apoptosis by a cadherin-dependent mechanism. Am J Physiol. 2000:278:758-68.

38. Carmeliet P, Lampugnani MG, Moons L, et al. Targeted deficiency or cytosolic truncation of the VE-cadherin gene in mice impairs VEGF-mediated endothelial survival and angiogenesis. Cell. 1999;98:147-57.

39. Tran NL, Adams DG, Vaillancourt RR, Heimark RL. Signal transduction from $\mathrm{N}$-cadherin increases $\mathrm{BCl}-2$. Regulation of the phosphatidylinositol 3-kinase/Akt pathway by homophilic adhesion and actin cytoskeletal organization. J Biol Chem. 2002;277:32905-14.

40. Cook D, Fry MJ, Hughes K, Sumathipala R, Woodgett JR, Dale TC. Wingless inactivates glycogen synthase kinase-3 via an intracellular signaling pathway which involves a protein kinase C. EMBO J. 1996;15:4526-36.

41. Cadigan KM, Nusse R. Wnt signaling: a common theme in animal development. Genes Dev. 1997;11:3286-305.

42. Klein $\mathrm{R}$, Nanduri $\mathrm{V}$, Jing $\mathrm{SA}$, et al. The trkB tyrosine protein kinase is a receptor for brain-derived neurotrophic factor and neurotrophin-3. Cell. 1991;66:395-403.

43. Douma S, van Laar T, Zevenhoven J, Meuwissen R, van Garderen v, Peeper DS. Suppression of anoikis and induction of metastasis by the neurotrophic receptor TrkB. Nature. 2004;430:1034-9. 